\title{
Metabolic Reprogramming and Intervention During T Cell Exhaustion
}

\author{
Fei $\mathrm{Li}^{1}$, Huiling $\mathrm{Liu}^{2}$, Dan Zhang ${ }^{1}$, and Bingdong Zhu ${ }^{1}$ \\ ${ }^{1}$ Lanzhou University \\ ${ }^{2}$ Gansu Provincial Hospital
}

September 24, 2021

\begin{abstract}
Recent studies have shown that $\mathrm{T}$ cell metabolism has become a key regulator of $\mathrm{T}$ cell function and even can determine $\mathrm{T}$ cell function at last. Naïve T cells use fatty acid oxidation (FAO) to meet their energetic demands. Effector T cells mainly rely on aerobic glycolysis to supply energy and synthesize intermediate products. Similar to naïve T cells, memory T cells primarily utilize FAO for energy. Exhausted T cells, which can be induced by continuous activation of $\mathrm{T}$ cells upon persistently chronic infections such as tuberculosis, mainly rely on glycolysis for energy. The prevention and treatment of $\mathrm{T}$ cell exhaustion is facing great challenges. Interfering $\mathrm{T}$ cell metabolism may achieve the goal of prevention and treatment of $\mathrm{T}$ cell exhaustion. In this review, we compiled the researches related to exhausted $\mathrm{T}$ cell metabolism and put forward the metabolic intervention strategies to reverse $\mathrm{T}$ cell exhaustion at different stages to achieve the purpose of preventing and treating $\mathrm{T}$ cell exhaustion.
\end{abstract}

\section{Hosted file}

manuscript 8.12. doc available at https://authorea.com/users/435730/articles/538549-metabolicreprogramming-and-intervention-during-t-cell-exhaustion 